\title{
Colonialismo tecnológico ou como podemos RESISTIR AO NOVO EUGENISMO DIGITAL - entrevista com Sérgio Amadeu Silveira
}

\author{
Felipe PADILHA* \\ Lara FACIOLI $I^{* *}$
}

\section{Contexto da entrevista}

Sérgio concedeu a entrevista a Felipe Padilha e Lara Facioli por e-mail, em abril de 2020, em meio às medidas de restrição de contato social impostas pela pandemia da Covid-19. A conversa é ambientada num contexto de adoção intensificada de tecnologias digitais e explora as conexões íntimas entre tecnologia e política, passando por tópicos como cultura, educação e as implicações das mídias digitais para a pesquisa acadêmica e para a vida das democracias contemporâneas.

\section{Apresentação do entrevistado}

Sérgio Amadeu Silveira é professor associado do Programa de Pós-Graduação em Ciências Humanas e Sociais da Universidade Federal do ABC (UFABC) e desenvolve pesquisas que transitam entre as áreas da Sociologia e da Ciência Política. Graduado em Ciências Sociais, mestre e doutor em Ciência Política pela Universidade de São Paulo (USP), há mais de duas décadas tem se dedicado a

\footnotetext{
UFSCar - Universidade Federal de São Carlos. Centro de Educação e Ciências Humanas. Departamento de Sociologia. Pesquisador Associado ao NAMCULT/ UFSCar - Núcleo de Estudos em Ambiente, Cultura e Tecnologia. São Carlos - SP - Brasil. 13565905 - felipeapa@yahoo.com.br. https:// orcid.org/0000-0002-5511-7252.

* FURG - Universidade Federal do Rio Grande. Campus Carreiros. Grupo de Pesquisa em Sociologia Digital. Carreiros - Rio Grande - RS - Brasil. 96203-900 - larafacioli@yahoo.com.br. https://orcid. org/0000-0003-4054-9631.
} 
compreender o novo cenário sociotécnico e político configurado a partir do advento da internet comercial. Pesquisador do CNPq, com bolsa produtividade em pesquisa, é membro do Comitê Científico Deliberativo da Associação Brasileira de Pesquisadores em Cibercultura (ABCiber). Sua trajetória acadêmica é marcada por temas de pesquisa como: as implicações tecnopolíticas dos sistemas algoritmos; Inteligência Artificial e ativismo; as relações entre comunicação e tecnologia; sociedades de controle e privacidade; práticas colaborativas na Internet.

É autor de dezenas de artigos e diversos livros, entre os quais destacam-se: Democracias e códigos invisíveis; Tudo sobre tod@s: redes digitais, privacidade e venda de dados pessoais; Exclusão Digital: a miséria na era da informação; Software Livre: a luta pela Liberdade do conhecimento. Além da expressiva produção acadêmica, Sérgio Amadeu da Silveira se mantém como uma voz ativa nos debates públicos, com engajamento nas iniciativas da sociedade civil que envolvem, sobretudo, a preservação de direitos nas mídias digitais, a garantia de liberdade, a luta contra violações de privacidade na internet e a produção de softwares livres.

Entre os anos de 2003 a 2005, integrou o Comitê Gestor da Internet no Brasil, para o qual retornou em 2017, cadeira que ocupou até o final de maio de 2020. Presidiu o Instituto Nacional de Tecnologia da Informação, vinculado à Casa Civil da Presidência da República, entre os anos de 2003 e 2005; além de ter atuado à frente da implementação dos Telecentros na América Latina, em 2004, durante o governo da prefeita da cidade de São Paulo, Marta Suplicy.

Felipe Padilha e Lara Facioli: Para começar nossa conversa, gostaríamos que você nos contasse um pouco sobre desenvolvimento técnico da internet pensando em situar as transformações no campo da cibernética que resultaram nos deslocamentos na esfera da informação e do controle. Como chegamos às consequências políticas inerentes ao recolhimento de dados que experimentamos hoje? De modo resumido, quais são as implicações da relação entre tecnologia, cultura e sociedade para nossa vida cotidiana?

Sérgio Amadeu Silveira: A cibernética avançou velozmente após a denominada Segunda Grande Guerra. Os grandes pensadores da comunicação e do controle como Nobert Wiener criaram as bases para as redes digitais do último quarto do século XX. A ideia da retroalimentação dos sistemas de controle, originados da cibernética, está na base dos protocolos TCP/IP considerados fundamentais para a existência da Internet. O filósofo Gilles Deleuze, na década de 1980, percebeu que a cibernética estava mudando o diagrama de poder das sociedades, por isso, caracterizou o período que passamos a viver de sociedades de controle. Quando 
me comunico com alguém na internet utilizo um dispositivo para enviar e receber informações para outro dispositivo técnico que está em algum ponto do planeta. Essa interação é realizada entre milhões de possibilidades e de rotas que compõem a internet. Entretanto, os dispositivos que interagem têm posições inequívocas na rede e assim a comunicação só pode ser realizada com base em um controle de precisão. Alexander Galloway havia dito que a internet é uma rede de controle jamais vista. Precisamos compreender bem esse processo por ser decisivo. É o controle técnico que nos permite enviar mensagens com o conteúdo que quisermos. Esse controle é que garante a liberdade de nos comunicarmos. Todavia, ele não só assegura que os ativistas pela democracia espalhem suas ideias e articulem movimentos em rede. $\mathrm{O}$ controle permite simultaneamente a vigilância e o rastreamento das ações. Aí está um ponto crucial. A internet é um arranjo tecnológico ambivalente. Para as redes cibernéticas recobrirem o planeta foi necessário além das condições técnicas, condições políticas e econômicas. A guerra fria deu um impulso em inventos e no avanço da comunicação distribuída. O neoliberalismo foi crucial para acelerar tecnologias úteis à transferência rápida de capitais. $\mathrm{O}$ avanço do capitalismo neoliberal e o fim da União Soviética culminou com a abertura de fronteiras e a intensificação do fluxo de capitais e das redes digitais. As privatizações de setores de infraestrutura, como o das telecomunicações gerou grandes oligopólios e intensificou níveis de disputa e destruição de barreiras no mundo que deveria ser transformado em um grande mercado global. Nick Srnicek mostra que os capitais nunca atingiram taxas de lucratividade do período anterior, conhecido como Welfare State. Então, os grupos que acumularam gigantescas quantias de capital abriram inúmeros experimentos que geraram crises, tais como a de 2008. O modelo de negócio que estava dando certo era o das empresas de tecnologia da informação, puxado pela expansão das redes digitais. Caso observemos minuciosamente esse período, poderemos notar que a voracidade dos capitais em busca de uma reprodução fácil e rápida é que gerou o crash nos negócios insustentáveis e milionários que existiam na internet no final dos anos 1990. Essa quebradeira ficou conhecida como "estouro da bolha da Internet" ou "quebra das ponto com" que ocorreu na queda livre das ações da maioria das empresas de tecnologia ou comércio eletrônico na Nasdak, em 2000. Foi aí que Google, Amazon e outras começaram a virada para a dataficação. Na primeira década do século XXI, a capacidade de processamento dos computadores e uma série de melhorias e novos inventos nos softwares, nos hardwares e na infraestrutura estavam ocorrendo, financiadas por especuladores em busca de rendimentos rápidos. Em paralelo, o avanço de soluções de aprendizado de máquina, um subcampo da chamada Inteligência Artificial, reforçou a crença de que a coleta de dados dos consumidores e usuários de serviços possibilitariam a extração de padrões de comportamento. O Google apostou no modelo que se baseia na entrega de interfaces e aplicativos gratuitamente para coletar dados das 
pessoas. Assim, começou a construção de enormes estruturas para o armazenamento e o processamento de dados pessoais com o objetivo de modular e prever as ações futuras de cada indivíduo. Modelos estatísticos preditivos serviram para estimular a confiança e a adesão dos capitalistas a essa lógica. A intensa competição pela atenção dos consumidores impelia os anunciantes a buscar microsegmentos e perfis específicos para apresentar sua propaganda. A lógica de vender para quem tem perfil para comprar foi se consolidando com base na oferta crescente de perfis cada vez mais detalhados. É certo que o neoliberalismo foi decisivo para isso. No livro O Nascimento da Biopolítica, Foucault tinha detectado que o neoliberalismo buscava colocar a empresa como a unidades básica da sociedade e a concorrência como seu ethos, mesmo onde essa competição não existisse, em mercados dominados por oligopólios e monopólios. Nada melhor para o mito da concorrência que tentar prever os passos, os gostos e os interesses futuros de seus consumidores atuais e futuros. Assim modelo de dataficação se intensificou e se tornou indispensável para o capitalismo neoliberal. Vivemos uma sociedade em rede como argumentou Manuel Castells na última década do século XX. Essas redes, físicas e lógicas, asseguram o rastreamento dos metadados de nossa navegação, a coleta massiva de dados pessoais transformando o capitalismo em um conjunto de dispositivos de vigilância e extração dos fluxos de dados. A vida está sendo dataficada como afirmou a pesquisadora Van Dijck. Estamos vivendo cada vez mais da predição e para as práticas preditivas.

Felipe Padilha e Lara Facioli: Tudo Sobre Tod@s e Democracias e Códigos Invisíveis são análises que podem ser lidas em continuidade, sobretudo, se considerarmos que os dois livros tratam de processos sociotécnicos de interação e controle, com implicações profundas para a democracia. Enquanto no primeiro livro a análise está centrada na dimensão dos mercados de dados pessoais online, o segundo trata da relação entre economia informacional e política. Nos últimos anos, especialmente nas Ciências Humanas, temos constatado uma intensificação dos debates em torno das articulações entre política e mídias digitais. Tendo em vista o atual contexto brasileiro, qual seria uma síntese possível sobre a relação entre dados pessoais digitais e política?

Sérgio Amadeu Silveira: A política voltada ao controle do Estado nas democracias liberais há muito é realizada com a mediação de profissionais de marketing. $\mathrm{Na}$ segunda década do século XXI, ela passou a incorporar também os cientistas de dados. Quando a televisão se popularizou no século XX, os partidos recorreram aos especialistas em propaganda televisiva para estruturar suas campanhas. Com o avanço da internet, com a enorme relevância das redes sociais online e das plataformas de entretenimento, as disputas políticas caminharam para as redes 
digitais e os especialistas em tecnologia passaram a ser fundamentais. O marketing comercial utiliza o chamado big data para minerar oportunidades e o machine learning para atuar sobre microssegmentos da sociedade e até mesmo para realizar a propaganda one-to-one, voltada exclusivamente para uma pessoa. O marketing político segue o caminho do marketing comercial. Se a chamada inteligência artificial passa a servir ao mercado publicitário e as plataformas online, ela também servirá à formação da opinião pública e às disputas eleitorais. Superdimensionado ou não, o fato é que o escândalo da Cambridge Analytica alertou todas as democracias para a gravidade do uso dos dados, das redes e da inteligência de máquina. Assim como os cientistas de dados de uma grande empresa de varejo buscam criar o perfil de seus potenciais consumidores e capturar o seu padrão de comportamento, adquirindo banco de dados variados, realizando cruzamentos e correlações de informações quantificadas com o objetivo de melhorar suas vendas, os dirigentes das campanhas eleitorais e políticas partirão para mapear e rastrear os cidadãos com a finalidade de construir o perfil de microssegmentos e de cada eleitor identificável. O problema está na transparência dos processos que na maioria dos casos ocorrem de modo imperceptível, invisível. Uma das questões mais complexas está no papel das plataformas de relacionamento-entretenimento. Não conhecemos seus algoritmos. Não sabemos como controlam a visualização dos conteúdos. Enfim, não podemos avaliar com precisão o processo de modulação dos comportamentos que realizam. A gestão das plataformas é realizada por sistemas algorítmicos e não somente por burocratas. O algoritmo do YouTube pode ter um viés ou até uma orientação de aumentar o alcance dos vídeos da extrema direita e isso terá enormes consequências na comunicação realizada a partir daquela plataforma. Quando as condições básicas de equidade da disputa pela formação da opinião são profundamente distorcidas e alteradas não podemos dizer que temos uma democracia. Essa é a hipótese do e-book que escrevi chamado Democracia e os Códigos Invisiveis. Considero três hipóteses de como os sistemas algoritmos podem afetar as sociedades democráticas. Primeiro, nos espaços online e nas chamadas redes sociais, eles podem atuar sobre as condições e procedimentos indispensáveis à existência da democracia. Os sistemas algorítmicos podem distorcer e alterar as condições mínimas e indispensáveis de equidade entre as forças políticas que disputam a opinião pública e o voto. Segundo, podem modular os processos de formação e de formatação da opinião pública, sem que isso seja transparente. A modulação é a principal técnica das plataformas, não sendo baseada no discurso, mas no controle do que se vê, se lê e se ouve. Terceiro, os sistemas algorítmicos atuam diretamente sobre a privacidade a partir da vigilância pervasiva dos dispositivos. A questão é que a democracia não pode conviver com tamanha opacidade e poder das corporações. 
Felipe Padilha e Lara Facioli: A opacidade em torno dos fluxos de dados cria problemas para a sociedade e também para as pesquisas. Isso quer dizer que a tarefa de compreender relações digitalmente mediadas, invariavelmente exige um deslocamento no desenho da pesquisa. Em uma dimensão empírica, muitas vezes, estamos lidando com sujeitos que fazem uso de um sistema operacional formal. Tal particularidade nos conduz a uma posição ambígua entre sujeitos e tecnologias, que exige das Ciências Sociais um esforço no sentido de elaborar uma compreensão formal da tecnologia e do seu funcionamento e, ao mesmo tempo, sobre a vida social contemporânea que se produz entrelaçada com a tecnologia. Essa questão fica mais complicada quando empregamos serviços de redes sociais como o Facebook e o Twitter em nossas pesquisas ou se percebermos como nossas buscas na internet são moduladas pelo Google. Seus trabalhos abordam de maneira crítica essa dimensão da opacidade dos sistemas, ou seja, de como os fluxos informacionais são controlados, modulados e organizados pelas plataformas. A dimensão de opacidade evidencia o quão limitado é o nosso conhecimento sobre os processos algorítmicos. Partindo dos desafios já apontados aqui, quais enfrentamentos você destacaria como fundamentais para a pesquisa social interessada nas mídias digitais?

Sérgio Amadeu Silveira: Temos inúmeros desafios epistemológicos. Quando cientistas de dados, estatísticos e profissionais de marketing extraem e realizam o tratamento de dados para forjar os perfis mais sensíveis à propaganda de um determinado produto, estamos observando aquilo que é equivalente a uma pesquisa social aplicada, a uma pesquisa experimental. A questão é saber qual a validade, o fundamento e o alcance da conversão ou expressão de toda a vida em um conjunto emaranhado de fluxos de dados. Até que ponto, podemos dizer que a detecção do nosso comportamento pode definir nossa subjetividade? Tudo pode ser resumido na filosofia e psicologia behaviorista. A correlação dos dados elimina a necessidade de causalidade e substitui as hipóteses e a pesquisa qualitativa? Entre os sociólogos e antropólogos há uma enorme desconfiança da dataficação. Contudo, é inegável que pesquisas sociais estão utilizando arranjos de big data para se aproximar de fenômenos complexos, que a teoria dos grafos está permitindo conhecer e classificar os grupos políticos que disputam redes digitais, que os algoritmos de linguagem natural estão melhorando as possibilidades da análise de discurso. Agora, note que nada disso é neutro ou natural, como o mercado quer nos fazer ver. Um dado não dá em árvore, nem é como o petróleo, um recurso natural. Dados são projetados. Dados antes de serem coletados precisam de um dispositivo de coleta. Pense em um RG ou CPF. São números simples que indexam inúmeras outras informações. Um RG não nasceu no meu quintal, nem veio ao mundo quando eu nasci. O RG foi criado pelos burocratas do Estado em um dado momento. Ele vincula determinadas informações e pode ser usado para me identificar. Mas o RG está longe de guardar 


\section{Colonialismo tecnológico ou como podemos resistir ao novo eugenismo digital - entrevista com Sérgio Amadeu Silveira}

qualquer revelação do meu ser. O mundo para ser dataficado precisa ser projetado. Hoje sabemos quais amigos dos meus amigos compram os meus livros. Essa categoria foi inventada, não pode ser naturalizada. Os meus likes nas postagens do Facebook viraram medidores de personalidade, como se o modo como capturam essa informação fosse neutro. A dataficação atual pode ser muito enganosa. A cientista ou o cientista social precisa ser mais crítico que nunca. Por exemplo, o psicólogo social Michal Kosinski e o cientista da computação Yilun Wang publicaram uma pesquisa em que utilizaram um algoritmo de deep learning (aprendizado de máquina profundo) para detectar o padrão de homossexualidade em pessoas fotografadas. Digitalizaram 30.000 rostos e conseguiram extrair um padrão biométrico do que seria um gay. Ao ser treinado com o padrão encontrado, o algoritmo atingiu um grau de precisão na identificação de $81 \%$ em homens e $71 \%$ em mulheres. Essa pesquisa gerou indignação pelos perigos que possui em um mundo com 12 países que consideram a homossexualidade um crime cuja pena é a morte. Além da dimensão ética da pesquisa, tenho uma pergunta: quer dizer que faltava ao higienista Cesare Lombroso apenas dados suficientes para sustentar suas teorias criminalistas baseadas na biometrização da criminalidade? Me parece que cabe às Ciências Sociais atuais desmistificar e desnaturalizar a dataficação. Precisamos atuar na episteme desses processos. Há um enorme risco social de uma nova eugenia a partir desses processos que colocam os dados como expressão fiel do real.

Felipe Padilha e Lara Facioli: Em 2014, após intensa luta contra interesses corporativos e políticos, o Brasil conseguiu projetar e implementar o Marco Civil da Internet, um conjunto valioso de leis que resguarda os direitos individuais na utilização da rede. Pode-se dizer que uma das principais conquistas alcançadas pela regulamentação foi a neutralidade da rede. Com isso, empresas ficam impedidas de selecionar ou filtrar a informação que circula por nossos cabos e provedores de conexão. Também foi igualmente vedado o armazenamento de dados de navegação de usuários. Em tese, trata-se de uma legislação democrática que garante a neutralidade, a segurança de dados e do fluxo de informação. Hoje, o que foi modificado e o que ainda temos daquelas garantias estabelecidas a partir do Marco Civil? Como você analisa a relação entre as grandes corporações, o controle de dados e as legislações nacionais?

Sérgio Amadeu Silveira: O Marco Civil da internet no Brasil foi a resposta da sociedade civil organizada ao marco criminal que era proposto pelo então Senador Eduardo Azeredo (PDSB) que reunia o apoio de segmentos do aparato de vigilância e das agências policiais do Estado. Após o 11 de setembro, o Departamento de Estado norte-americano incentivava diversos países a aprovar leis duras que criminalizariam práticas cotidianas na internet. Contra isso, surgiu a ideia de 
lançar uma lei que garanta direitos e deveres na utilização da internet. Com base em princípios democráticos e de garantia de liberdades e direitos individuais e coletivos fundamentais foi lançada a primeira versão da proposta de Marco Civil. É preciso destacar que nesse momento, a formulação do Marco Civil na gestão do então presidente Lula representou uma grande novidade. O projeto de lei começou com uma versão submetida a consulta em uma plataforma do Ministério da Cultura, desenvolvida em software livre. O processo de elaboração do Marco Civil contou com duas rodadas de coleta de propostas, recebendo mais de 2 mil contribuições. Depois de sistematizado pelo Ministério da Justiça o projeto foi enviado ao Congresso, já na gestão da presidenta Dilma Rousseff. Na Câmara dos Deputados, o projeto original sofreu diversos ataques das forças retrógradas, dos banqueiros, dos defensores do copyright e de representantes das operadoras de telecom. O princípio da neutralidade da rede esteve no centro dos embates. O Marco Civil queria proibir que o controlador da infraestrutura da internet pudesse interferir no fluxo de dados que passava pelos seus cabos e fibras ópticas. Em sentido oposto, as operadoras de telecomunicações pretendiam criar na internet o modelo de negócios semelhante ao da TV a cabo e cobrar por tipo de uso das aplicações de rede. Para acessar o e-mail e a web você pagaria menos do que para acessar aplicações multimídia, tais como som e vídeo. Mas, a sociedade civil organizada queria que o controlador da fibra óptica fosse neutro em relação aos conteúdos que passam por ela. Assim, as teles não poderiam discriminar o tráfego de pacotes de bits por ideologia, posição política, raça, religião, nem pelo tipo de aplicação. Os provedores de conexão, as teles, estariam autorizadas a vender pacotes de velocidade diferentes, mas uma vez que alguém comprou um pacote de $20 \mathrm{Mbits}$ poderia acessar qualquer aplicação, e-mail, vídeo, etc. Os defensores de modelos de negócio que dependem da quebra da neutralidade passaram ao ataque. Disseram que a neutralidade protegia os gamers que usavam muita banda e que faziam a sociedade pagar pela diversão desses moleques e nerds. Muitos que hoje são bolsonaristas convictos apoiaram esses argumentos falaciosos. O próprio Bolsonaro foi o único deputado que votou contra o Marco Civil com o argumento curioso de "defesa da liberdade" contra "a ditadura na internet". Aquilo que parecia incoerente e até engraçado, nonsense já era uma estratégia política da extrema direita neofascista. Só conseguimos aprovar o Marco Civil contra o lobby das agências de vigilância, dos banqueiros, da indústria de copyright e das Teles graças às denúncias realizadas por Snowden do aparato de espionagem da NSA, em junho de 2013. Alemanha e Brasil foram os dois países mais espionados. A agência de inteligência digital dos EUA havia espionado pessoas comuns e autoridades, como Angela Merkel e Dilma Rousseff. Até a denúncia de Snowden, o governo brasileiro não dava muita importância à internet e ao Marco Civil. O Ministro das Comunicações de Dilma era muito sensível ao argumento das teles. Quando o projeto de lei voltou a andar na Câmara foram feitos diversos 
acordos para que fosse aprovado. O Marco Civil é a melhor lei sobre a internet já aprovada em qualquer país, mas tem várias brechas. Partidos de direita como o PPS (formado por ex-membros do Partido Comunista) exigiram que a polícia tivesse acesso ao cadastro de usuários de provedores de acesso, sem ordem judicial. Apesar de tudo isso, o Marco Civil assegura que a remoção de conteúdos e a identificação de IPs (endereços de navegação) só possam ocorrer com ordem judicial. Ao contrário do que disse Bolsonaro no momento da aprovação do Marco Civil, com a aprovação da lei, nenhuma autoridade do Executivo, policial e até o presidente da República pode obter dados de um usuário sem ordem judicial. Isso fortaleceu o estado de direito e incomoda até hoje muitos adeptos do novo e do velho pensamento reacionário. Após o golpe de 2016, inúmeros projetos de lei tentam desfigurar o Marco Civil. Os ataques ocorrem principalmente contra a defesa da privacidade, a proteção dos cidadãos contra as investidas do aparato policial. Agora os ataques partem de quem ingenuamente quer combater as chamadas fake news, destruindo princípios básicos e direitos fundamentais que estão no Marco Civil. Não será destruindo direitos que conseguiremos parar as máquinas de desinformação da extrema direita. Em sentido indesejado muitas vezes pelos ingênuos, a destruição dos direitos civis terá o efeito oposto.

Felipe Padilha e Lara Facioli: Pode-se dizer que, no Brasil, a relação íntima entre os meios de comunicação e pessoas que ocupam ou ocuparam cargos políticos, seja na esfera do poder municipal, estadual ou federal, deita raízes históricas. Por exemplo, em 2016, o Sistema de Acompanhamento de Controle Societário da ANATEL constatou que, no país, 32 deputados e 8 senadores eram declaradamente proprietários, sócios ou associados de canais de rádio e televisão. Neste mesmo ano, uma ação penal, embasada na Constituição, foi encaminhada ao Supremo Tribunal Federal (STF), solicitando a vedação de vínculos desse tipo. Como essas relações entre poder político e meios de comunicação avançaram e se renovaram com as mídias digitais? Em algum momento do passado recente, o acesso à internet foi mais aberto e democrático do que é hoje? Podemos considerar o contexto eleitoral de 2018 como um marco para pensar mídias digitais, internet e política no Brasil?

Sérgio Amadeu Silveira: A internet inverteu efetivamente os fluxos de comunicação. Com ela, o difícil não é falar, o difícil é ser ouvido. A economia da difusão foi rivalizada por uma economia da atenção. Essa possibilidade de qualquer pessoa com o mínimo de habilidade criar um site, um blog, um vídeo, um conteúdo, realmente democratizou a fala. Isso trouxe muitas ilusões. Como já havia alertado ainda no século XX, o professor Langdon Winner, não é porque alguém consegue voar de asa delta que será páreo para enfrentar a Força Aérea dos EUA. Com essa imagem, Winner deixava claro que existem elementos complexos que as tecnologias nos 
trazem e não podemos simplificá-los. Considero que existe uma crise profunda sobre a internet. Essa crise possui três dimensões que se articulam. A primeira é a crise da estrutura das redes distribuídas. A segunda pode ser chamada de crise do ideal da participação. A terceira é a crise do livre fluxo dos dados. A arquitetura da internet não é centralizada. É composta de inúmeras camadas. Sem centros lógicos de passagem de dados obrigatório, a Internet é uma rede distribuída. Isso gerou uma confusão. Muitos analistas acreditaram que algo distribuído seria inerentemente democrático. Hoje, sabemos que não. Uma rede distribuída pode ser democrática no acesso de diversos pontos, mas pode distribuir também a vigilância e o controle social a partir de um de seus nós. Uma rede tecnicamente distribuída não impede a concentração de tráfego e das atenções em poucos nós. O fato de ser distribuída não impede a atuação do capital, não bloqueia o poder dos endinheirados, nem das grandes corporações. A segunda crise é a da crença na participação digital. O fato da rede estar disponível para milhões de pessoas não implica que elas participem de processos democratizantes. Além disso, nem toda a participação nas redes visa construir a democracia, muito menos é voltada ao entendimento, como queria Habermas. A extrema direita tem utilizado a internet para disseminar o discurso de ódio, para articular milícias digitais, realizar linchamentos de reputação, destilar ideias misóginas, racistas, homofóbicas, distribuir a desinformação como parte de uma estratégia política de explodir as possibilidades de um debate racional baseado em fatos. Isso tem levado a apressada e estranha posição de ortodoxos marxistas em criticar a participação nas redes. Jogam fora uma excelente placa de circuitos porque o HD queimou. Esquecem que a participação em rede permitiu a articulação dos quilombolas, das comunidades indígenas, de diversos grupos democráticos, permitiu a emergência do Podemos, entre outros milhares de exemplos. A participação é fundamental para mudar a sociedade. Sem dúvida, nem toda a participação política tem como objetivo fortalecer a democracia e a equidade. Pode ser de articulação de um MBL, das milícias digitais da família de Bolsonaro, pode montar as ações da KKK e da supremacia branca. A terceira crise envolvendo a internet é a que denomino de crise do livre fluxo de dados. É certo que a internet é uma rede transnacional e isso é positivo. Todavia, isso não implica que todos os dados do Brasil precisem ser daqui extraídos e levados para os data centers na Califórnia, na China ou para qualquer estrutura das corporações do mundo rico. $\mathrm{O}$ acesso a conteúdos de sites, os metadados fundamentais para a navegação livre na internet devem ser assegurados por todos os países. Isso não autoriza uma empresa a enviar dados coletados de nossas crianças, a partir de aplicações cedidas às escolas, para os armazéns de dados das corporações estadunidenses, europeias ou chinesas. Os democratas norte-americanos na gestão Obama estavam preparando uma ofensiva na $\mathrm{OMC}$ para denunciar como ataque à liberdade de expressão e à livre iniciativa dos países que protegem os dados de suas populações. A vitória de Trump atrapalhou 
essa estratégia porque o bufão norte-americano é contra a $\mathrm{OMC}$ e as agências multilaterais. Isso atrasou a pressão dos EUA pela extração livre de dados. Essa questão nos remete ao problema que alguns pesquisadores têm chamado de novo colonialismo ou colonialismo de dados. Os pesquisadores Couldry e Mejias definem o colonialismo de dados como uma ordem emergente de apropriação da vida humana como fluxo de dados que podem ser continuamente extraídos para a obtenção de lucro. A internet tem sido o principal meio, não o único, para as plataformas capitalistas obterem os dados de populações de todo o planeta.

Felipe Padilha e Lara Facioli: Encerrado o período eleitoral de 2018, houve uma expansão do debate sobre o funcionamento das mídias digitais, sobretudo, a partir da circulação direcionada de notícias falsas - fake news -, e, com isso, veio à tona a questão do poder dos algoritmos. Sérgio, você pode falar um pouco sobre as relações entre recolhimento de dados e a modulação da opinião pública? Como essas relações se expressam na prática? Quais exemplos empíricos de recolhimento de dados podemos mencionar? Podemos considerar que a sociedade está mais preparada para lidar com as dinâmicas conectadas?

Sérgio Amadeu Silveira: O que podemos falar com base na empiria é o seguinte: existem grupos políticos que distribuem informações completamente distorcidas utilizando redes digitais, principalmente, não-exclusivamente, pelo Whatsapp, cujo controle democrático é dificultado pelo modelo de negócios do seu controlador o Facebook. O Youtube também é utilizado por esses grupos para passar informações mentirosas e descontextualizadas. A técnica mais comum utilizada pelos "influencers" da extrema direita é a de descontextualização. Por exemplo, é comum esses personagens mostrarem um livro e afirmarem que o conteúdo traz algo que não está escrito. Entretanto, como a grande maioria não vai ler o livro, o fato de mostrar a capa dá uma certa veracidade ao argumento equivocado ou completamente inverídico. Como as plataformas por onde se distribui essa desinformação é operada ou gerenciada por sistemas algorítmicos opacos, invisíveis, fechados à análise de auditorias independentes, não podemos comprovar que elas estariam privilegiando o discurso de ódio ou as posições extremistas. Podemos provar que as hordas bolsonaristas produzem desinformação em massa. Elas reúnem os grupos que propõe a eliminação física do outro, como a supremacia branca, os nazistas, neointegralistas. Recentemente, o presidente da República fez um vídeo tomando leite e logo foi seguido pelos seus seguidores nas redes. Tomar leite em público é um símbolo dos supremacistas brancos. Esses grupos se ligam ao autoritarismo neoliberal que também possuem fábricas de fake news, um dos tipos de desinformação. Propagam clássicos totalitários, tais como, "o holocausto não existiu", "o nazismo era de esquerda", "não existe racismo no Brasil", com mentiras 
como "o filho de Lula é dono da Friboi", “o Greenpeace jogou óleo no mar", "as ONGs colocaram fogo na Amazônia". O fato é que até a Justiça já possui o mapa das fábricas de desinformação. Todavia, não há consenso em uma questão fundamental: exageros e mentiras são comuns na política, no entanto, o fenômeno atual é bem diferente disso. Enquanto acreditarmos que a desinformação é um post feito pela tia ou pelo priminho estaremos sem nenhuma condição de enfrentar esse processo sociotécnico. Enquanto pensarmos que a desinformação é um fenômeno distribuído por todo espectro político estaremos atuando de modo errático. A desinformação é a estratégia dos chamados neorreacionários, da direita alternativa, alt-right, que prefiro chamar de neofascismo ou fascismo neoliberal. Essa estratégia ganhou o coração de líderes obscuros da extrema direita norte-americana e se espalhou entre o que vem sendo chamado de novo populismo da direita. Não desinformam porque acreditam no conteúdo do que espalham ou porque erraram. A desinformação é a estratégia de anular o debate baseado em fatos para levá-lo para o plano da crença, dos valores. Nick Land, filósofo dos neorreacionários, considera que o iluminismo anulou os valores importantes e o racionalismo nos conduz ao marxismo ocidental. Por isso, os debates com base nos fatos e na razão conduziriam ao esquerdismo, ao agigantamento do Estado. Assim, cabe aos neorreacionários destruírem esse modelo argumentativo e substituí-lo pela defesa da família, da redução do Estado, pelo patriotismo, pela religião. Não é por menos que os evangélicos neopentecostais, que dão muito valor ao dinheiro, estão praticamente alinhados com Bolsonaro e com o neoliberalismo reacionário, antidemocrático mais devastador. Esses grupos não vão parar de desinformar. A desinformação faz parte de sua estratégia central. Agora, falar que a Cambridge Analytica venceu as eleições para Trump é algo que precisa ser comprovado. Sem dúvida, a desinformação tem um efeito na esfera pública automatizada, gerenciada por algoritmos e organizada por plataformas obscuras que vendem as pessoas em amostras. Qual nível de efeito? Estamos estudando isso. É preciso não confundir isso com o lawfare organizado no Brasil pelas forças em torno dos tucanos, da Globo e do capital financeiro cuja maior expressão é a Operação Lava Jato. O lawfare, utilização das estruturas judiciais para perseguir pessoas ou grupos políticos, no Brasil, empregou o exagero, a corrupção das funções essenciais da Justiça, a partidarização do Ministério Público e a condenação com suposições ou com provas pífias ou forjadas. Mas, nem mesmo a Globo insiste em manter determinadas versões completamente descontextualizadas da dupla Moro-Dallagnol. Sem dúvida, a Globo protege e esconde os abusos do seu paladino Moro, mas ela não aderiu à estratégia da extrema direita de aniquilar completamente o debate baseado nos fatos. Omitem, escondem, fazem de conta que não sabiam, proíbem o uso de determinadas expressões, vetam a entrevista com certas pessoas, utilizam modelos clássicos de desinformação de massas. Qual seria a diferença? Está na disposição de aceitar a comprovação factual. Para os neoliberais do PSDB a ciência tem validade, 
os fatos comprovados devem ser reconhecidos. Para a extrema direita bolsonarista e seus fundamentalistas evangélicos, a comprovação dos fatos e a realidade não tem a menor relevância. Por isso, um capitão e um general, sem nenhuma formação em saúde pública, sentem-se à vontade para prescrever cloroquina para pessoas com Covid-19. Para os neoliberais que ainda não romperam com a democracia, para a direita conservadora tradicional, a ciência deve ser respeitada. Já para os neorreacionários a ciência está dominada pelos marxistas e deve ser confrontada. Pior que as fake news é a fake science. Enfim, a internet e as plataformas de relacionamento online com seu modelo de monetização e de venda de amostras foi extremamente útil para que empresários extremistas usassem seus milhões para articular o neofascismo com a população.

Felipe Padilha e Lara Facioli: Enquanto realizamos esta entrevista, o mundo enfrenta a pandemia provocada pela Covid-19, que tem deixado um rastro de mortes e colapsos nos sistemas de saúde dos países mais afetados. Nessa semana, que se inicia no dia 6 de abril, espera-se que o Brasil alcance um novo platô de contágio, que deve levar a uma sobrecarga nos atendimentos do Sistema Único de Saúde (SUS) e também dos sistemas privados. As consequências da pandemia envolvem, de maneira direta, o uso das tecnologias digitais na esfera do trabalho, da socialidade cotidiana e mesmo nos espaços de cultura e lazer. Considerando que tratamos de um cenário caótico, que pode ser usado para justificar a tomada de medidas de policiamento digital por parte dos governos com algum apelo entre parte da população, e sabendo que essas tecnologias trabalham com recolhimento constante de dados e com modulação, como você tem refletido sobre essas mudanças e sobre os prováveis efeitos que experimentaremos no contexto pós-pandemia? Como refletir sobre os impactos diversos do isolamento, da intensificação dos usos dessas tecnologias, tanto no âmbito das dinâmicas sócio-econômicas e políticas, quanto em termos de transformações subjetivas?

Sérgio Amadeu Silveira: Para evitar o contágio de um vírus que é transmitido por pessoas assintomáticas, que pode ficar dias em roupas, bancos, fechaduras é preciso adotar medidas sanitárias duras e que podem contrariar alguns interesses individuais. Essa é a dimensão biopolítica do poder de Estado. Entretanto, nesse mundo digitalizado, estamos vendo corporações - que vivem da coleta de dados e da construção de perfis para a venda altamente lucrativa de amostras de microssegmentos sociais - aproveitarem o momento para expandir a coleta e o armazenamento de dados pessoais. Até empresas de ciberguerra e espionagem como a NSO ofereceram aos governos tecnologias de acompanhamento de celulares para o rastreamento em tempo real do deslocamento da população e para a identificação de supostos infectados. Quero ir direto ao ponto. Vivo na cidade de São Paulo. Aqui, 
existem áreas de grande adensamento populacional, sem saneamento básico e com carência de água. As moradias são precárias e em muitas delas temos quatro pessoas vivendo em dois cômodos. O acesso dentro de algumas favelas é realizado em vielas muito estreitas. Dada a carência nos hospitais públicos, pessoas que chegam com alguns sintomas não são internadas e voltam para suas casas. Não existem protocolos de isolamento de pessoas com suspeita de ter contraído a doença para residências precárias. Não estamos fazendo testes massivamente na população. Não sabemos quem está portando o vírus. Mas os governos acham moderno inserir aplicativos nos celulares ou acompanharem o deslocamento da população. Para que serve isso? Para muito pouco. As tecnologias que podemos adotar para evitar o contágio não estão sendo utilizadas. Melhor do que entregar dados dos celulares seria colocar mais ônibus em circulação para evitar que pessoas sejam transportadas de pé sem o distanciamento mínimo. Cuba e Nova Zelândia, o primeiro com quase nenhuma tecnologia digital e o segundo com mais dispositivos digitais, arregimentaram médicos, estudantes, agentes de saúde para visitar as residências e acompanhar diariamente o estado de saúde das pessoas. No Brasil, o movimento popular está trabalhando com agentes que visitam territórios e levam termômetro, oxímetro e equipamentos EPI para visitar as moradias precárias. A Uniafro está fazendo mais no enfrentamento do novo coronavírus do que os mapas de calor, supostamente anonimizados obtidos pelo Senhor Dória. Munido de um celular o agente de saúde liga para uma médica ou médico contratado pelo movimento para esclarecer as dúvidas do pessoal que está atuando na ponta. Mas, as plataformas e os corretores de dados, os vendedores de câmeras de vigilância ligadas aos sistemas de inteligência artificial não querem perder a oportunidade de obter os valiosos dados de celular, de desempenho escolar e de saúde das pessoas. O lucro do Facebook no primeiro trimestre de 2020 subiu $18 \%$. As escolas e universidades estão entregando dados dos seus estudantes, técnicos e professores para as plataformas que vivem do comércio de dados pessoais. Podemos utilizar tecnologias de modo a preservar os direitos humanos e a melhorar nossa situação. A violação de direitos não melhora o enfrentamento da pandemia. Além disso, seus efeitos colaterais podem trazer inúmeras sequelas para a democracia.

Felipe Padilha e Lara Facioli: A política de substituição das aulas presenciais por um modelo de educação a distância $(\mathrm{EaD})$ tem ganhado celeridade na esteira da crise provocada pela pandemia da Covid-19, sobretudo, no estado de São Paulo. Você tem se levantado como uma das vozes críticas a este processo. Sua argumentação parte da desigualdade brasileira e de como essa desigualdade não está restrita apenas ao plano econômico, mas também se expressa no plano social e educacional. Uma das questões centrais no debate sobre $\mathrm{EaD}$ diz respeito ao acesso à internet no Brasil. Dados da Pesquisa Nacional por Amostra de Domicílios (PNAD) Contínua, realizada 
em 2018, mostram que entre os segmentos mais pauperizados da população, ou seja, aqueles com renda inferior a 3 salários mínimos, o acesso à internet é realizado por celular em 54\% dos lares. A maioria faz uso de planos pré-pagos. Uma das soluções apresentadas pelos governos estaduais tem sido o estabelecimento de parcerias público privadas envolvendo as Secretarias da Educação e as grandes corporações de telecomunicações. Ao menos em tese, a promessa é que, a partir desta aliança, o acesso gratuito às aulas online estará garantido. Mas, como fica a questão da extração de dados nesse contexto? Quais são os riscos para os estudantes e professores, na medida em que estamos novamente lidando com sistemas opacos, sobre os quais pouco sabemos? Quais garantias temos de que não haverá extração de dados ou de que os dados extraídos de estudantes e professores não serão utilizados à serviço do poder público ou privado?

Sérgio Amadeu Silveira: Como já venho argumentando, estamos aprofundando a nossa condição de colônia digital. Não somos capazes de manter os dados de nossas crianças, alunas e alunos em nossas instituições de ensino. Ouvi de um empresário a objeção de que eu estava duvidando da honestidade do Google e da Microsoft. Respondi que não tinha a menor intenção de duvidar da seriedade dessas corporações, o que eu não duvidava e afirmava com todas as letras é que o modelo de negócios delas se baseia na coleta de dados pessoais para a análise e venda em amostras para quem quiser comprar. A pesquisadora Shoshana Zuboff considera o Google como uma empresa que inaugurou o capitalismo de vigilância. Ela define o capitalismo em que vivemos como um sistema que reivindica unilateralmente a experiência humana como matéria-prima livre para tradução em dados comportamentais. Eu considero que nessa pandemia, na área de Educação, estamos vivendo o embate entre a lógica neoliberal e a lógica decolonial. Fiquei muito feliz em participar da assembleia virtual de professores convocada pela associação de docentes da minha universidade. Os grupos de trabalho apresentaram um texto com propostas para a Reitoria com a finalidade de organizarmos como serão nossas atividades daqui para frente. Entre as sugestões está a realização de um censo sociotécnico e de vulnerabilidades de alunas, alunos, professoras, professores, técnicas e técnicos. Esse censo será fundamental para construirmos uma plataforma própria a partir das carências e necessidades do processo de ensino que seja eficaz e socialmente inclusivo. Temos capacidade técnica para utilizar códigos abertos para formar uma plataforma que não retire nossos dados. Qual seria o grande entrave? A infraestrutura de conexão, o número de servidores disponíveis e a banda colocada para o acesso das diversas pessoas? Podemos utilizar uma infraestrutura federada? Talvez. O importante é que se a Reitoria concordar podemos articular outras universidades para construirmos essa plataforma de ensino e aprendizado online. Enquanto o governo federal assina um acordo absurdo com a Cisco, sem licitação, para mapear as universidades e pesquisas 
com inteligência artificial, o governo de São Paulo, entre outros, entrega os dados de nossas crianças para plataformas que vivem da extração de padrões para a venda de amostras de perfis aos departamentos de marketing. Mas não é de graça? Não. As interfaces e soluções excepcionais que essas plataformas nos entregam custam bem menos do que elas ganham com a extração e tratamento dos nossos dados pessoais. O futuro será decidido em meio da pandemia. Temos que começar a reagir contra o colonialismo tecnológico. Temos opções. Existem inúmeros desenvolvedores de soluções abertas inteligentes e eficazes. Resta saber se temos vontade de enfrentar a segregação dos pobres, o racismo algorítmico, a violação da privacidade e o novo eugenismo digital.

\section{REFERÊNCIAS}

FOUCAULT, Michel. O nascimento da Biopolítica. São Paulo: Martins Fontes, 2008.

SILVEIRA, Sérgio Amadeu Democracias e códigos invisíveis: como os algoritmos estão modulando comportamentos e escolhas políticas. São Paulo: Edições Sesc, 2019. Coleção Democracia Digital. Disponível em: https://play.google.com/books/ reader?id=Wb2ZDwAAQBAJ\&hl=en_US\&pg=GBS.PT9. Acesso em: 08 jul. 2020.

SILVEIRA, Sérgio Amadeu. Tudo sobre tod@s: redes digitais, privacidade e venda de dados pessoais. São Paulo: Edições Sesc, 2017. Disponível em: https://play.google.com/books/ reader?id=Hj0qDwAAQBAJ\&hl=en_US. Acesso em: 08 jul. 2020.

SILVEIRA, Sérgio Amadeu. Software Livre: a luta pela Liberdade do conhecimento. São Paulo: Fundação Perseu Abramo, 2004. Disponível em: https://fpabramo.org.br/publicacoes/ estante/software-livre-a-luta-pela-liberdade-do-conhecimento/. Acesso em 08 jul. 2020.

SILVEIRA, Sérgio Amadeu. Exclusão Digital: a miséria na era da informação. São Paulo: Fundação Perseu Abramo, 2001. 